\title{
The Development and Validation of a New Questionnaire to Address the Gap between the Actual and Desired States in COPD Patients
}

\author{
Motegi $\mathrm{T}^{1^{*}}$, Takahashi $\mathrm{T}^{2}$, Katsura $\mathrm{H}^{3}$, Ichinose $\mathbf{M}^{4}$ and Nagai $\mathrm{A}^{5}$ \\ ${ }^{1}$ Respiratory Care Clinic, Nippon Medical School, Tokyo, Japan \\ ${ }^{2}$ Department of Internal Medicine, Tohoku Medical and Pharmaceutical University Wakabayashi Hospital, Sendai, Japan \\ ${ }^{3}$ Division of Respiratory Medicine, Tokyo Women's Medical University Yachiyo Medical Center, Yachiyo, Japan \\ ${ }^{4}$ Department of Respiratory Medicine, Tohoku University Graduate School of Medicine, Sendai, Japan \\ ${ }^{5}$ Respiratory Research Center, Shinyurigaoka General Hospital, Kawasaki, Japan
}

*Corresponding author:Takashi Motegi, Respiratory Care Clinic, Nippon Medical School, 4-7-15-8F Kudanminami, Chiyoda-ku, Tokyo, Japan, Tel: +81-3-5276-2325; Fax: +81-3-5276-2326; E-mail: mo-dr@nms.ac.jp

Received date: July 22, 2016; Accepted date: August 18, 2016; Published date: August 25, 2016

Copyright: (c) 2016 Motegi T, et al. This is an open-access article distributed under the terms of the Creative Commons Attribution License, which permits unrestricted use, distribution, and reproduction in any medium, provided the original author and source are credited.

\section{Abstract}

Background: Numerous quality of life (QOL) assessment tools are available for patients with chronic obstructive pulmonary disease (COPD); however, most only focus on the patient's actual state, and very few assess the patient's desired state.
\end{abstract}

Objective: To develop a questionnaire that can assess COPD patients' desired states and to verify the usefulness of the findings.

Methods: We interviewed COPD patients to identify components that best reflected the patients' desired movement/activities. Two types of questionnaires were created with each component intended for self-assessment by actual and desired states. The revised questionnaire included the appropriate components based on the results of the preliminary survey. A multicenter study was performed using the final questionnaire.

Results: We selected 32 components of the patients' desired movement/activity from interviews with 22 COPD patients. The final questionnaire consisted of eight components and had a sufficiently high internal consistency (Cronbach's $\alpha>0.8$ ). Three hundred and sixty two COPD patients participated in the validation study. The gap score (the difference between actual and desired scores) was significantly correlated with the predicted percentage of the forced expiratory volume in $1 \mathrm{~s}$, dyspnea scale, and the COPD assessment test (CAT) $(p<0.0001)$. Oxygen therapy and frequent exacerbations exhibited unfavorable gap scores $(p<0.001)$. Multiple regression analysis on actual scores identified dyspnea scale, CAT, oxygen use, unemployment, exacerbation and heart failure to be independent explanatory variables (adjusted $\mathrm{R}^{2}=0.63$ ). Whereas only dyspnea scale and CAT were significant predictors in gap score (adjusted $\mathrm{R}^{2}=0.32$ ).

Conclusion: The gap and actual scores evaluate the different aspect of the patients' state. Evaluating the gap scores in patients might be useful in the assessment of the suitability of ongoing medical interventions and in the determination of future therapeutic goals.

Keywords: COPD; QOL; Gap; Questionnaire

\section{Abbreviations:}

HRQOL: Health Related Quality of Life; COPD: Chronic Obstructive Pulmonary Disease; CAT: COPD Assessment Test; PROs: Patient-Reported Outcomes; $\mathrm{FEV}_{1}$ : Forced Expiratory Volume in 1 Second; FVC: Forced Vital Capacity; mMRC: Modified Medical Research Council; 6MWT: 6-Minute Walking Test; LTOT: Long-Term Oxygen Therapy; CHF: Chronic Heart Failure; SDs: Standard Deviations

\section{Introduction}

Chronic Obstructive Lung Disease (COPD) is a global health problem and Japan is no exception. The incidence rate of COPD in
Japan is 0.81 per 100 person-years for males and 0.31 per 100 personyears for females, and increases significantly with age. Its incidence rate in Japan is similar to those reported in Europe [1]. The population of Japan is expected to shrink from 128 million in 2005 to 95 million in 2050 , while the proportion of people aged 65 years or older is expected to rise to $40 \%$ [2]. Because of this expected increase in the number of older adults, it is necessary to maintain good communication with elderly patients to continue the treatment of chronic diseases. Humanistic approach, respect, and people-focused attitude are critical for good communication with COPD patients [3].

Furthermore, the importance of improving health related quality of life (HRQOL) and preventing future risks has been emphasized for the management of patients with COPD in the Global Initiative for Chronic Obstructive Lung Disease (COLD) document and the Japanese Respiratory Society guidelines [4,5]. Therefore, it is 
imperative to evaluate the HRQOL of patients with COPD in common practice.

The term QOL covers a wide variety of concepts and there is no consensus on its definition. QOL is dependent on the similarity of the patient's desires to their actual experience and can be improved by reducing the gap between the desired state and the actual state [6]. Furthermore, the World Health Organization defined QOL as the "individuals' perceptions of their position in life in the context of the culture and value systems in which they live and in relation to their goals, expectations, standards, and concerns" [7]. Numerous QOL assessment methods are based on this basic concept, from generic types to disease-specific types, and such methods for COPD are presently close to becoming established.

To assess the HRQOL in COPD patients, the St. George's Respiratory Questionnaire [8] and the Chronic Respiratory Disease Questionnaire [9] have been established as disease-specific tools. These have been utilized in the assessment of not only the pharmacological effects of new drugs, but also a variety of other aspects including the effects on disease worsening [10], rehabilitation [11], and correlation with the outcomes [12]. More recently established tools include those that are universally simple and easy-to-use, such as the COPD assessment test (CAT) [13]. These HRQOL assessment tools provide important information concerning the patient-reported outcomes (PROs) and objectively present one aspect of the patient's condition.

However, these tools do not generally focus on the extent to which the patients want to improve their well-being or their desired health condition [14]. Studies that focus on the patient's desires are limited. The desired physical condition of a COPD patient will be dependent on various factors, including disease severity and living conditions. Furthermore, setting a therapeutic goal by incorporating an individual's unique desires would be useful in planning specific actions in daily life.

In the present study, we developed a new-approach questionnaire for the evaluation of patients' desires to help determine a COPD therapy goal from the patient's perspective.

\section{Methods}

Two studies were performed. Study I involved the development and validation of a new questionnaire, and Study II involved a large-scale validation of the new questionnaire in related facilities. Patients with COPD from authors' institutions and from the institutions participating in the Japan Asthma and COPD management Forum (JASCOM) were recruited in the present study. The inclusion criteria were the medical diagnosis of COPD, post-bronchodilator forced expiratory volume in 1 second $\left(\mathrm{FEV}_{1}\right)$ /forced vital capacity (FVC) $<70 \%$, at least 40 years of age, and history of smoking for at least 10 pack-years.

\section{Study I: The questionnaire development}

A flow chart representing the questionnaire development process is presented in Figure 1. We initially conducted a survey on COPD patients under routine practice to understand their desired living conditions. Based on these results, we selected the appropriate components to create an initial version of the questionnaire where each component had to be answered considering both the actual and desired states. After conducting a preliminary survey using the initial version, we created a modified version of the questionnaire by limiting it to a smaller set of components and by adopting a five-point assessment scale. Subsequently, cluster analysis was performed to finalize the questionnaire.

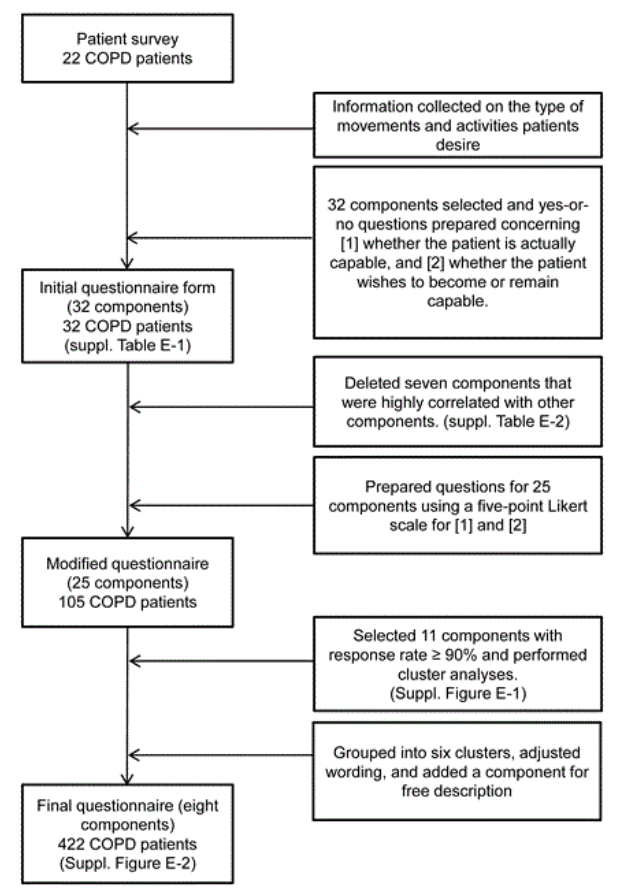

Figure 1: A flow chart depicting the questionnaire development process in Study I. COPD, chronic obstructive pulmonary disease.

Initial patient interview: A qualitative focus-group interview was conducted among a sample population of symptomatic adults with COPD. Twenty-two subjects aged 55-77 years were recruited from the Tokyo metropolitan or Kansai regions. The patients were divided into 5 age groups containing 4 or 5 patients each ( 3 groups in Tokyo: 50s, 60s, and 70s; 2 groups in Kansai: 50-60s and 60-70s). Each interview was conducted over a period of $2 \mathrm{~h}$. Patients were asked to speak freely about their desired activities and daily living conditions. The patients were particularly questioned on their present concerns and what they wanted to do in the future. The interviews were audio-recorded and content analysis was applied to the transcripts in order to derive the item pool. Based on the information obtained from the audio recordings, we extracted the movements and activities desired by the patients. These interviews were carried out based on the advice of the Japan Management Association.

Initial questionnaire: The first version of the questionnaire consisted of the initial patient interview components involving two types of questions: 1) 'yes' or 'no' questions relating to the ability of the patient to perform a specific movement/activity, and 2) 'yes' or 'no' questions relating to the patient's desire to perform a specific movement/activity or the maintenance of performing that movement/activity. Using the first version of the questionnaire, we subsequently conducted a 
preliminary survey among COPD patients treated as outpatients at the Tohoku Medical and Pharmaceutical University Wakabayashi Hospital.

The modified questionnaire: The modified questionnaire contained some of the first version components that were selected based on the results of the preliminary survey. Each component was answered according to a 5-point Likert scale for actual and desired states (completely capable-0 point, highly capable-1 point, somewhat capable-2 points, poorly capable-3 points, not capable-4 points). Using this modified version, we conducted another preliminary survey on the COPD patients from the authors' five institutions.

Preparation of the final questionnaire: To reduce the number of items in the modified questionnaire, we selected the components that achieved at least a 90\% response rate (thereby allowing high discrimination). After item selection, cluster analysis was performed using the Ward method [15]. We created a final questionnaire based on this result. The difference between the actual state score and the desired state score was defined as the gap score.

\section{Study II: Cross-sectional survey}

Using the final version of the questionnaire, we conducted a crosssectional survey of outpatients diagnosed with COPD at 25 institutions participating in the JASCOM between January and March 2013. We also investigated the lung function $\left(\mathrm{FEV}_{1} / \mathrm{FVC}\right.$ and $\mathrm{FEV}_{1} \%$ predicted), CAT scores, modified Medical Research Council (mMRC) dyspnea scale scores, 6-min walking test (6MWT) results, co-morbidities, longterm oxygen therapy utilization, frequency of exacerbations in the previous year, employment status, and family composition of each patient surveyed. The severity of airflow obstruction was classified as stage I, II, III, or IV depending on the percentage of the predicted postbronchodilator $\mathrm{FEV}_{1} \%$. Exacerbation was defined as "an acute event characterized by the worsening of the patient's respiratory symptoms that is beyond the normal day to day variation and leads to a change in medication", in the Japanese Respiratory Society COPD guidelines [5]. Data regarding exacerbations were collected using chart-review at each institution.

The diagnosis of any comorbidity was confirmed by either reviewing the patient's medication list, or when feasible by confirmatory tests available from their medical records. Ten comorbidities were identified in all patients: Hypertension, diabetes mellitus, ischemic heart disease, chronic heart failure (CHF), cerebrovascular disease, any malignant disease, gastrointestinal disease, osteoporosis, and depression. All patients provided written informed consent before participating in the study.

\section{Statistical analysis}

Cronbach's alpha coefficient was computed to assess the internal consistency within the questionnaire components. A high internal consistency suggests that the scale or subscale measures a single construct. A value $<0.70$ indicates that individual items provide an inadequate contribution to the overall scale.Descriptive analysis included calculating means and standard deviations (SDs). We tested the relationship between the questionnaire score and clinical parameters using the Spearman correlation test. Non-parametric tests for independent samples (The Mann-Whitney $U$ Test for two groups and Kruskal-Wallis Test for three or more groups) were employed to test for differences.
For the prediction of the actual, desired, and gap scores, a stepwise multiple regression analysis was performed using variables that were identified to be significant in the single regression analysis. All variables with $\mathrm{p}$-values $<0.25$ were entered into the regression model according to the stepwise approach, while all variables with p-values $>0.10$ were removed. Data were analyzed using the JMP v.10 (Japanese version) software and $\mathrm{p}$-values $<0.05$ were considered statistically significant.

\section{Results}

\section{Study I}

From the initial patient interview, we selected 32 components of the patients' desired movements and activities for the initial version of the questionnaire. Using this questionnaire, a preliminary survey was conducted with 32 COPD patients at the Tohoku Medical and Pharmaceutical University Wakabayashi Hospital (Supplementary Table E-1). Based on these results, we modified the questionnaire by selecting 25 components through the exclusion of seven that were highly correlated with other components (Supplementary Table E-2). The Cronbach's alpha coefficient for the 25 components was 0.883 , indicating satisfactory internal consistency. Using the 25-component questionnaire, a second preliminary survey was conducted with 105 COPD patients from five affiliated institutions. Based on this questionnaire outcome, we selected 11 components that achieved at least $90 \%$ response rates. Finally, cluster analysis was conducted using these 11 components.

At the end of the cluster analysis, 11 components were grouped into six clusters: 1) Going-out activities (Q12 and Q14); 2) Moderate activities (Q8, walking on stairways); 3) Vigorous activities (Q9, carrying a heavy item); 4) Pace of activity (Q16, performing an activity at a pace similar to unaffected individuals in the same age group); 5) Activities of daily living (Q1, 2, \& 4; sleeping and eating); and 6) Activities of daily living (Q5, 6, \& 3; bathing and using the toilet) (Supplementary Figure E-1).

Taking this as reference, we added an extra component for the patient to freely describe a specific desired hobby/sport, and adjusted the questions and overall wording. Finally, we prepared the final version of the questionnaire comprised of eight components (Supplementary Figure E-2).

In the final version, the total score range could be $0-32$ points for both the actual and desired states; larger scores indicated a more unfavorable state.

\section{Study II}

We retrieved the completed questionnaires from 422 patients. Among them, 24 exhibited normal $\mathrm{FEV}_{1} / \mathrm{FVC}$ levels; 36 had incomplete information (8 patients forgot to fill out the forms while the data of the remaining 24 patients were missing); and the remaining 362 patients were included in the final analysis.

Overall patient characteristics: The overall patient characteristics are summarized in Table 1 . The majority of patients were aged in their 70s, $74 \%$ had $\% \mathrm{FEV}_{1}$ of $30-80$, and the mean patient CAT score was 14.6 points. At the time of the survey, $22 \%$ of the patients were employed and $31 \%$ did not have a spouse. 
Citation: Motegi T, Takahashi T, Katsura H, Ichinose M, Nagai A (2016) The Development and Validation of a New Questionnaire to Address the Gap between the Actual and Desired States in COPD Patients. Lung Dis Treat 2: 113. doi:10.4172/2472-1018.1000113

Page 4 of 8

\begin{tabular}{|c|c|}
\hline Variables & $n=362$ \\
\hline Male/Female/unknown & $328 / 31 / 3$ \\
\hline Age, $Y$ & $73.2(8.1)$ \\
\hline $\mathrm{FEV}_{1.0} \mathrm{~L}$ & $1.35(0.58)$ \\
\hline$\% \mathrm{FEV}_{1.0} \%$ & $57.7(23.5)$ \\
\hline$\geq 80$ & $64(17.7)$ \\
\hline $50-79$ & $133(36.7)$ \\
\hline $30-49$ & $134(37)$ \\
\hline$<30$ & $31(8.6)$ \\
\hline Modified MRC dyspnea scale & $2.6(1.0)$ \\
\hline 0 & $50(14)$ \\
\hline 1 & $136(38)$ \\
\hline 2 & $104(29)$ \\
\hline 3 & $56(15.6)$ \\
\hline 4 & $12(3.3)$ \\
\hline Unknown & $4(0.1)$ \\
\hline $6 M W D, m(n=110)$ & $358(150.6)$ \\
\hline CAT & $14.6(8.3)$ \\
\hline Exacerbation rate/year & 0.53 \\
\hline $0-1$ & $310(85.6)$ \\
\hline 2 & $44(12.2)$ \\
\hline Unknown & $8(2.2)$ \\
\hline LTOT use, yes & $62(17.2)$ \\
\hline Currently employed, yes & $77(22.5)$ \\
\hline Marital status-single & $114(31.5)$ \\
\hline \multicolumn{2}{|c|}{ Data are presented as number, mean (SD), or number (\%) } \\
\hline \multicolumn{2}{|c|}{$\begin{array}{l}\text { 6MWD: } 6 \text { Minutes Walking Distance; CAT, COPD assessment test } \\
\text { Exacerbation rate, previous exacerbation rate; FEV } 1.0 \text { : Forced Expiratory } \\
\text { Volume in } 1 \mathrm{~s} \text {; MRC: Medical Research Council; LTOT: Long-term Oxygen } \\
\text { Therapy; SD: Standard Deviation }\end{array}$} \\
\hline
\end{tabular}

Table 1: Patient characteristics.

The score distribution patterns: The mean scores $( \pm S D)$ of the actual state scores, desired state scores, and gap scores were $10.8( \pm 10.0), 5.0$ $( \pm 4.0)$, and $5.7( \pm 4.7)$, respectively. The Cronbach's alpha coefficient was favorable at $0.887,0.870$, and 0.846 for the actual state scores, desired state scores, and gap scores, respectively. The distribution pattern for the gap scores is plotted as bar charts in Supplementary Figures E-3 and E-4.

The mean actual and desired state scores indicated a relatively small gap between the actual and desired states for components related to the basic activities of daily living, such as eating and bathing (Q4 and Q5). The data revealed a greater gap for components related to activities more vigorous than the activities of daily living (Figure 2).

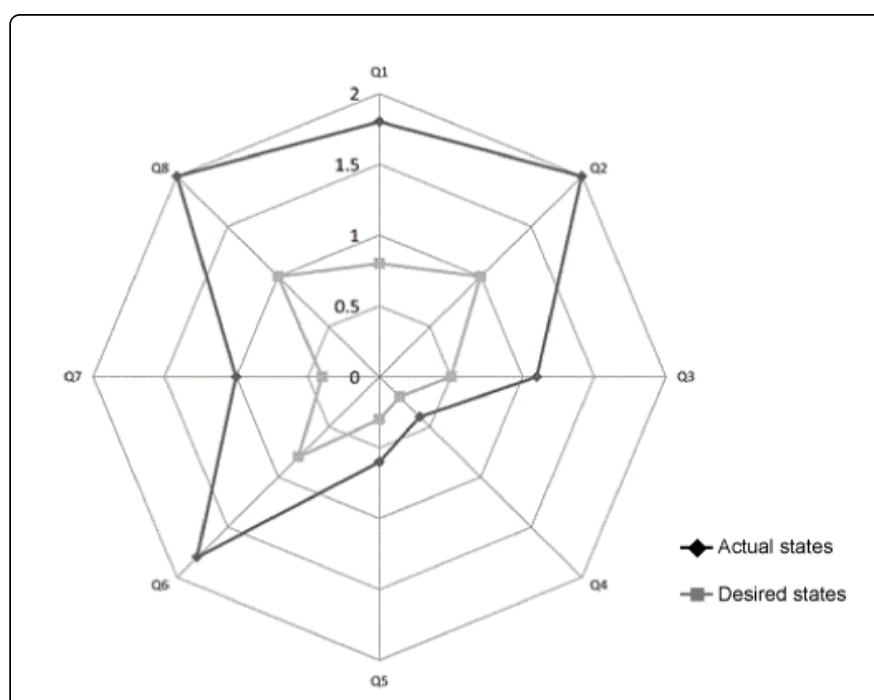

Figure 2: Comparisons between the mean actual and desired state scores for the eight questionnaire components.

The relationship between each component score and clinical parameters: The actual state scores, desired state scores, and gap scores significantly correlated with $\% \mathrm{FEV}_{1}(\mathrm{rho}=-0.436,-0.313$, and -0.315 , respectively; all $\mathrm{p}<0.0001$ ), $\mathrm{mMRC}$ dyspnea scale scores ( $\mathrm{rho}=0.674$, 0.451 , and 0.508 , respectively; all $\mathrm{p}<0.0001$ ), and CAT scores (rho $=$ $0.654,0.430$, and 0.512 , respectively; all $\mathrm{p}<0.0001$ ) (Table 2 ).

\begin{tabular}{|l|l|l|l|l|l|l|}
\hline \multirow{2}{*}{} & \multicolumn{2}{|l|}{ Actual state score } & \multicolumn{2}{l|}{ Desired state score } & \multicolumn{2}{l|}{ Gap score } \\
\cline { 2 - 7 } & rho & $\mathbf{p}$-value & rho & $\mathbf{p}$-value & rho & p-value \\
\hline Age & 0.166 & 0.002 & 0.183 & 0.0005 & 0.041 & 0.443 \\
\hline \%FEV 1 & -0.436 & $<0.0001$ & -0.313 & $<0.0001$ & -0.315 & $<0.0001$ \\
\hline 6MWD & -0.587 & $<0.0001$ & -0.544 & $<0.0001$ & -0.276 & 0.005 \\
\hline mMRC & 0.674 & $<0.0001$ & 0.451 & $<0.0001$ & 0.508 & $<0.0001$ \\
\hline CAT & 0.654 & $<0.0001$ & 0.43 & $<0.0001$ & 0.512 & $<0.0001$ \\
\hline
\end{tabular}

6MWD: 6 Minutes Walking Distance; CAT: COPD Assessment Test; FEV : Forced Expiratory Volume in $1 \mathrm{~s}$; mMRC: Modified Medical Research Council

Table 2: The correlation between each questionnaire score and clinical parameters.

Patient age was weakly correlated with actual scores $(\mathrm{rho}=0.166 ; \mathrm{p}$ $=0.0016)$ and desired state scores ( $\mathrm{rho}=0.183 ; \mathrm{p}=0.0005)$, but not with gap scores. Employment status had an impact on the gap score; working patients exhibited a smaller gap score, indicating a favorable state $(\mathrm{p}=0.0016)$. Patients utilizing long-term oxygen therapy, and those with frequent exacerbation showed a greater gap, indicating an unfavorable state ( $p<0.0001$ and $p=0.0009$, respectively). In contrast, patient sex and being married did not correlate with any of the scores. In co-morbidities, $\mathrm{CHF}$ and osteoporosis were significantly higher for the actual and desired scores, and depression was significantly higher for only the desired scores. However, there were no comorbidities that caused significant differences in the gap score (Table 3). 
Citation: Motegi T, Takahashi T, Katsura H, Ichinose M, Nagai A (2016) The Development and Validation of a New Questionnaire to Address the Gap between the Actual and Desired States in COPD Patients. Lung Dis Treat 2: 113. doi:10.4172/2472-1018.1000113

Page 5 of 8

\begin{tabular}{|c|c|c|c|c|}
\hline \multicolumn{2}{|l|}{ Clinical character } & \multirow{2}{*}{$\begin{array}{l}\text { Actual state score } \\
10.6(6.8)\end{array}$} & \multirow{2}{*}{$\begin{array}{l}\text { Desired state score } \\
4.9(4.7)\end{array}$} & \multirow{2}{*}{$\begin{array}{l}\text { Gap score } \\
5.6(4.8)\end{array}$} \\
\hline & Male $(n=328)$ & & & \\
\hline & Female $(n=31)$ & $12.5(7.8)$ & $5.4(5.1)$ & $7.1(5.2)$ \\
\hline \multirow{2}{*}{ LTOT } & Yes $(n=62)$ & $18.0(6.5)^{\mathrm{a}}$ & $9.6(5.0)^{a}$ & $8.4(5.3)^{\mathrm{a}}$ \\
\hline & No $(n=298)$ & $9.2(5.9)^{\mathrm{a}}$ & $4.1(4.1)^{\mathrm{a}}$ & $5.2(4.6)^{a}$ \\
\hline \multirow{2}{*}{ Exacerbation rate } & $0-1(n=310)$ & $9.9(6.5)^{\mathrm{a}}$ & $4.6(4.5)^{\mathrm{a}}$ & $5.4(4.7)^{\mathrm{a}}$ \\
\hline & $\geq 2(n=52)$ & $16.2(7.5)^{a}$ & $8.2(5.3)^{a}$ & $8.0(5.4)^{a}$ \\
\hline \multirow{2}{*}{ Employed } & Yes $(n=77)$ & $7.9(5.8)^{\mathrm{a}}$ & $3.6(3.6)^{a}$ & $4.3(4.2)^{\mathrm{a}}$ \\
\hline & No $(n=265)$ & $12.0(6.9)^{\mathrm{a}}$ & $5.7(4.9)^{\mathrm{a}}$ & $6.3(5.0)^{\mathrm{a}}$ \\
\hline \multirow{2}{*}{ Single } & Yes $(n=42)$ & $11.0(7.6)$ & $5.1(5.1)$ & $6.0(4.9)$ \\
\hline & No $(n=320)$ & $10.6(6.6)$ & $5.0(4.6)$ & $5.6(4.8)$ \\
\hline \multicolumn{5}{|l|}{ Co-morbidity } \\
\hline \multirow{2}{*}{ Ischemic heart disease } & Yes $(n=30)$ & $11.3(7.5)$ & $5.1(5.1)$ & $6.1(5.4)$ \\
\hline & No $(n=332)$ & $10.7(6.8)$ & $5.0(4.7)$ & $5.7(4.8)$ \\
\hline \multirow{2}{*}{ Chronic heart failure } & Yes $(n=18)$ & $16.1(7.2)^{a}$ & $9.8(5.9)^{a}$ & $6.3(4.0)$ \\
\hline & No $(n=344)$ & $10.4(6.8)^{a}$ & $4.8(4.5)^{\mathrm{a}}$ & $5.7(4.9)$ \\
\hline \multirow{2}{*}{ Hypertension } & Yes $(n=99)$ & $11.5(7.2)$ & $5.3(4.9)$ & $6.1(4.8)$ \\
\hline & No $(n=263)$ & $10.5(6.8)$ & $4.9(4.7)$ & $5.6(4.9)$ \\
\hline \multirow{2}{*}{ Cerebrovascular disease } & Yes $(n=12)$ & $13.1(5.8)$ & $5.7(6.1)$ & 7.4(3.9) \\
\hline & No $(n=350)$ & $10.7(6.9)$ & $5.0(4.7)$ & $5.7(4.9)$ \\
\hline \multirow{2}{*}{ Diabetes mellitus } & Yes $(n=33)$ & $12.9(7.6)$ & $6.0(6.2)$ & $6.9(5.6)$ \\
\hline & No $(n=329)$ & $10.6(6.8)$ & $4.9(4.6)$ & $5.6(4.8)$ \\
\hline \multirow{2}{*}{ Gastrointestinal disease } & Yes $(n=55)$ & $10.5(6.9)$ & $4.1(4.0)$ & $6.4(4.8)$ \\
\hline & No $(n=307)$ & $10.8(6.9)$ & $5.2(4.9)$ & $5.6(4.9$ \\
\hline \multirow{2}{*}{ Bronchial asthma } & Yes $(n=58)$ & $11.8(7.9)$ & $6.1(5.8)$ & $5.7(5.1)$ \\
\hline & No $(n=304)$ & $10.6(6.7)$ & $4.8(4.5)$ & $5.8(4.8)$ \\
\hline \multirow{2}{*}{ Malignant disease } & Yes $(n=31)$ & $10.5(7.5)$ & $4.8(4.8)$ & $5.7(5.5)$ \\
\hline & No $(n=331)$ & $108(6.8)$ & $5.0(4.7)$ & $5.7(4.8)$ \\
\hline \multirow{2}{*}{ Osteoporosis } & Yes $(n=20)$ & $15.4(8.2)^{\mathrm{a}}$ & $9.1(5.5)^{\mathrm{a}}$ & $6.4(4.0)$ \\
\hline & No $(n=342)$ & $10.5(6.7)^{\mathrm{a}}$ & $4.8(4.6)^{\mathrm{a}}$ & $5.7(4.9)$ \\
\hline \multirow{2}{*}{ Depression } & Yes $(n=13)$ & $13.0(5.3)$ & $7.8(4.5)^{\mathrm{b}}$ & $5.1(3.6)$ \\
\hline & No $(n=349)$ & $10.7(6.9)$ & $4.9(4.7)^{b}$ & $5.7(4.9)$ \\
\hline
\end{tabular}

Table 3: Comparison of each questionnaire score according to clinical characteristics. 
Citation: Motegi T, Takahashi T, Katsura H, Ichinose M, Nagai A (2016) The Development and Validation of a New Questionnaire to Address the Gap between the Actual and Desired States in COPD Patients. Lung Dis Treat 2: 113. doi:10.4172/2472-1018.1000113

Page 6 of 8

The comparison of gap scores stratified by disease severity (based on $\left.\% \mathrm{FEV}_{1}\right)$ indicated a significant increase in the gap scores with increasing disease severity (Mean gap score $( \pm \mathrm{SD})$; Stage $\mathrm{I}=3.6( \pm 3.5)$, $\mathrm{II}=5.3( \pm 4.7), \mathrm{III}=6.4( \pm 4.7), \mathrm{IV}=9.0( \pm 6.2))$. Similarly, gap scores increased with increasing CAT score or mMRC dyspnea scale score (Figure 3).

(a)

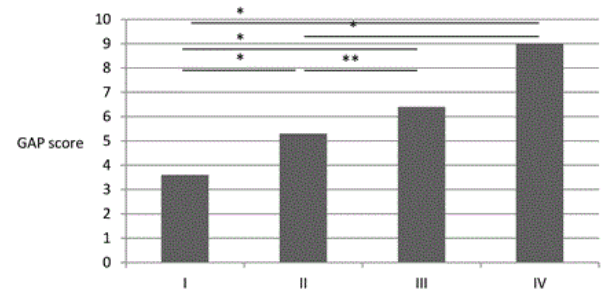

(b)

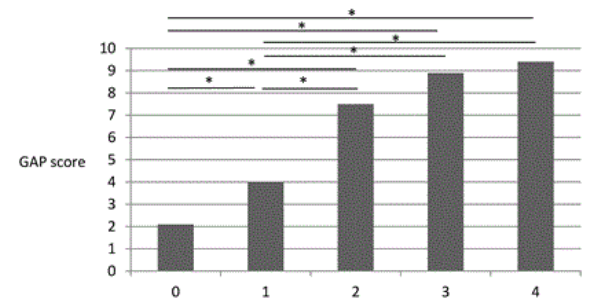

(c)

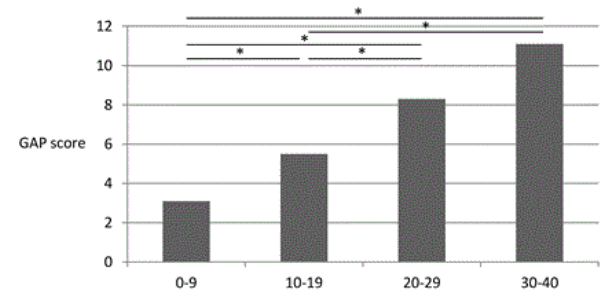

Figure 3: Comparison of gap scores stratified by pulmonary function and severity of symptoms.

Regression analysis: Multiple regression analyses were conducted to identify the factors significantly associated with the actual, desired, and gap scores. To predict the actual and desired scores as dependent variables, 10 independent variables (age, sex, mMRC dyspnea scale, CAT score, $\% \mathrm{FEV}_{1}$, oxygen consumption, frequent exacerbation, employment status, CHF, and osteoporosis) were included in the regression model. The significant predictors of actual scores were identified to be mMRC, CAT, oxygen consumption, unemployment, frequent exacerbation, and CHF (adjusted $\mathrm{R}^{2}=0.629$; Table 4).

The results for the desired score were similar to those for the actual score excluding the contribution of the exacerbation and employment status to the regression model. Furthermore, eight independent variables (age, sex, mMRC dyspnea scale, CAT score, oxygen use, frequent exacerbation, and employment status) were included in the regression model to predict the gap score. Although the gap score identified $\mathrm{mMRC}$ and CAT as independent explanatory variables, the adjusted $R^{2}$ of the regression model was a quite low value $\left(R^{2}=0.317\right.$; Table 4).

\begin{tabular}{|c|c|c|c|c|c|}
\hline $\begin{array}{l}\text { Scores/ } \\
\text { variables }\end{array}$ & Beta & $\begin{array}{l}\text { Standard } \\
\text { error }\end{array}$ & $p$ value & $F$ & $\begin{array}{l}\text { Adjusted } \\
\mathbf{R}^{2}\end{array}$ \\
\hline \multicolumn{4}{|l|}{ Actual score } & 82 & 0.629 \\
\hline mMRC & 2.219 & 0.298 & $<0.0001$ & & \\
\hline CAT & 0.34 & 0.033 & $<0.0001$ & & \\
\hline LTOT use, yes & 1.332 & 0.344 & 0.0001 & & \\
\hline $\begin{array}{l}\text { Employment } \\
\text { status, Yes }\end{array}$ & -0.909 & 0.286 & 0.0016 & & \\
\hline $\begin{array}{l}\text { Frequent } \\
\text { exacerbation }\end{array}$ & -0.786 & 0.332 & 0.0185 & & \\
\hline CHF, Yes & -1.134 & 0.514 & 0.0281 & & \\
\hline \multicolumn{4}{|l|}{ Desired score } & 34.4 & 0.366 \\
\hline CAT & 0.131 & 0.029 & $<0.0001$ & & \\
\hline LTOT use, Yes & 1.472 & 0.306 & $<0.0001$ & & \\
\hline mMRC & 0.985 & 0.258 & 0.0002 & & \\
\hline CHF, Yes & -1.321 & 0.472 & 0.0054 & & \\
\hline $\begin{array}{l}\text { Osteoporosis, } \\
\text { Yes }\end{array}$ & -1.196 & 0.438 & 0.0067 & & \\
\hline Age & 0.057 & 0.026 & 0.0294 & & \\
\hline \multicolumn{4}{|l|}{ Gap score } & 39.8 & 0.317 \\
\hline mMRC & 1.135 & 0.263 & $<0.0001$ & & \\
\hline CAT & 0.215 & 0.031 & $<0.0001$ & & \\
\hline $\begin{array}{l}\text { Employment } \\
\text { status, Yes }\end{array}$ & -0.522 & 0.27 & 0.0539 & & \\
\hline $\begin{array}{l}\text { Frequent } \\
\text { exacerbation }\end{array}$ & -0.341 & 0.31 & 0.2732 & & \\
\hline
\end{tabular}

Table 4: Multiple regression analysis of the actual, desired, and gap scores.

\section{Discussion}

The currently available HRQOL assessment tools generally focus on the present state of a patient. In contrast, our questionnaire, in addition to assessing the patient's present state, evaluated the patient's desired state by quantitatively assessing the gap between the actual and desired states. This type of approach is not part of the conventional evaluation of COPD patients and therefore represents the most important feature of our questionnaire.

Some studies have investigated the relationship between patients' QOL and desires, primarily in the field of cancer research [16,17]. Wan et al. conducted a survey of QOL in cancer patients using the Functional Assessment of Cancer Therapy-General questionnaire and reported that the gap between the desired level and actual level for each patient significantly correlated with the HRQOL. Based on this finding, the authors emphasized the importance of providing sufficient 
information on the risk, efficacy, and outcome of therapies beforehand and to have each patient set a realistic goal [16].

Welham et al. evaluated the difference between reality and desire using the "QOL gap" in psychiatric patients and found that the QOL gap was more correlated with the patient's satisfaction level than with QOL alone. The authors suggested that the QOL gap assessment could aid in therapeutic and research fields because it has the potential to focus on the patient's desired therapeutic goal [18]. Furthermore, a recent report applied the concept of gap evaluations to the interviewbased QOL assessment of children with chronic diseases; however, its clinical significance has not been established [19]. Our gap scoring system is also likely to play a similar role to previously reported methods, and the evaluation of its clinical significance in future studies is required.

In our cross-sectional survey, the gap score significantly correlated with the parameters related to the severity of COPD, including $\% \mathrm{FEV}_{1}$, mMRC dyspnea scale scores, CAT scores, home oxygen therapy, and frequent exacerbations. Our results revealed that these parameters were not only associated with the actual state of the COPD patients, but also with the gap between the desired and the actual states. Furthermore, multivariate analysis demonstrated that CAT and breathlessness were more significant explanatory variables than the frequency of disease worsening or employment status. These two measures have been emphasized in the symptom assessment of COPD patients following the revision of GOLD 2011 [3]. It has been reported that CAT can appropriately evaluate disease worsening [20] and progress in rehabilitation [21]. A close correlation between the mMRC dyspnea scale score and prognosis has also been reported [22]. Since these two parameters are highly associated with the gap score, medical interventions that improve these parameters are expected to achieve the therapeutic goals of patients to some extent. In the future, we recommend conducting a longitudinal study to follow the changes in gap evaluations before and after intervention.

As expected, multiple regression analysis was able to predict $63 \%$ of the actual score by conventional clinical factors (e.g. dyspnea severity, hypoxia, exacerbation). However, only $32 \%$ of the gap scores could be explained by similar clinical factors. In other words, these results suggest that predicting the patient's desire using standard clinical information is difficult. At the same time, our results confirm that this questionnaire evaluates a new aspect of patient data.

It was speculated that patient satisfaction was associated with the gap score. According to a study conducted by Fan et al., disease severity assessed by physical limitations and symptom burden was only weakly associated with general satisfaction. In contrast, factors such as education, coping skills, or disease perception were consistently associated with greater general satisfaction concerning the care provided [23]. A large gap score was attributed to the severity of COPD and it could be an indication of unsatisfactory medical intervention. This suggests that intervention has to be increased if the patient QOL is unfavorable and if the gap score is large. In addition, it is possible to attribute unfavorable QOL to the differences between medical facilities; therefore, assessment of the quality of facilities might be useful in evaluating the quality of care from the perspective of the patient, in order to meet the patient's standards.

Clinician-patient communication is one of the elements that contribute to patient satisfaction. The enhancement of communication helps develop treatment goals for patients with COPD [24]. Our new questionnaire allows the assessment of patient feelings, which can be used to improve the communication between the clinician and the patient. Because patient satisfaction was not assessed in this study, future studies should aim to focus on the gap score and its relationship with patient satisfaction.

Although comorbidities had no effect on the gap score, some were significantly higher for the actual or desired state scores. If a difference is reflected on the actual and desired state scores in the presence or absence of complications, this indicated that there was no difference in the patient's desire level. It should be noted that the meaning of these results is completely different compared to that for the oxygen using/ exacerbation rate affected gap scores. It is imperative to conduct further studies to interpret the differences in these three scores.

The GAP score was significantly poor for unemployed patients. A study conducted in Netherlands by Orbon et al. showed that patients with paid employment developed equal severity of airflow obstruction, but had a better QOL compared to patients who were unable to work [25]. Another study from Sweden showed that the self-reported QOL of patients with COPD was associated with social support and economic problems [26]. In the United States, employed adults with COPD reported significantly lower QOL and work productivity, and increased healthcare resource utilization than employed adults without COPD [27]. This suggests that working could serve as rehabilitation and may improve the QOL of patients with COPD [28]. The effect of employment status should be compared between the developed and developing countries.

The present study has several limitations. First, these results might be biased because the surveys were limited to Japanese patients with different lifestyles, religious beliefs, and attitudes towards hobbies and sports compared to patients from different countries. Therefore, these findings need to be verified in patients from different countries and ethnic groups. Second, the variation in the gap score attributable to the therapeutic intervention is unknown because we only performed a cross-sectional survey. The next research step should be to evaluate whether this gap can be reduced by therapeutic intervention.

\section{Conclusion}

We developed a new questionnaire style for the evaluation of the gap between the actual and desired states of COPD patients. The evaluation of differences between the desired and actual states of a patient is likely to aid the assessment of the suitability of ongoing medical intervention and might help determine future therapeutic goals.

\section{Acknowledgment}

The present study was conducted at selected medical institutions participating in the Japan Asthma and COPD management Forum. We deeply appreciate the cooperation and support of the physicians at these participating institutions. We sought advice from the Japan Management Association for the qualitative interview and cluster analysis.

\section{Author Contributions}

TM, TT, and HK were involved in the design of the study, data collection, and interpretation. MI and AN were involved in the design and interpretation of the study. TM was involved in data analysis. All authors contributed to the writing of the manuscript and they have approved the final version for submission. 
Citation: Motegi T, Takahashi T, Katsura H, Ichinose M, Nagai A (2016) The Development and Validation of a New Questionnaire to Address the Gap between the Actual and Desired States in COPD Patients. Lung Dis Treat 2: 113. doi:10.4172/2472-1018.1000113

Page 8 of 8

\section{Disclosures}

GlaxoSmithKline KK (GSK) funded the present study and was involved in all stages of the study protocol development except the writing of this manuscript. GSK has not been involved in the publication costs of the present manuscript. All authors took the responsibility of submitting this manuscript for publication.

\section{References}

1. Kojima S, Sakakibara H, Motani S, Hirose K, Mizuno F, et al. (2007) Incidence of chronic obstructive pulmonary disease, and the relationship between age and smoking in a Japanese population. J Epidemiol 17: 54-60.

2. Ikeda N, Saito E, Kondo N, Inoue M, Ikeda S, et al. (2011) What has made the population of Japan healthy? Lancet 378: 1094-1105.

3. Booker R (2005) Effective communication with the patient. Eur Respir Rev 14: 93-96.

4. Vestbo J, Hurd SS, Agusti AG, Jones PW, Vogelmeier C, et al. (2013) Global strategy for the diagnosis, management, and prevention of chronic obstructive pulmonary disease: GOLD executive summary. Am J Respir Crit Care Med 187: 347-365.

5. The Japanese Respiratory Society (2013) Guidelines for the Diagnosis and Treatment of COPD (4th edn.) Tokyo: Medical Review.

6. Calman KC (1984) Quality of life in cancer patients-a hypothesis. J Med Ethics 10: 124-127.

7. WHOQOL group (1995) The world health organization quality of life assessment (WHOQOL): position paper from the World Health Organization. Soc Sci Med 41: 1403-1409.

8. Jones PW, Quirk FH, Baveystock CM, Littlejohns P (1992) A selfcomplete measure of health status for chronic airflow limitation: The St George's respiratory questionnaire. Am Rev Respir Dis 145: 1321-1327.

9. Williams JEA, Singh SJ, Sewell L, Morgan MDL (2003) Health status measurement: sensitivity of the self-reported Chronic Respiratory Questionnaire (CRQ-SR) in pulmonary rehabilitation. Thorax 58: 515-518.

10. Seemungal TA, Donaldson GC, Paul EA, Bestall JC, Jeffries DJ, et al. (1998) Effect of exacerbation on quality of life in patients with chronic obstructive pulmonary disease. Am J Respir Crit Care Med 157: 1418-1422.

11. Spruit MA, Singh SJ, Garvey C, ZuWallack R, Nici L, et al. (2013) An official American Thoracic Society/European Respiratory Society statement: Key concepts and advances in pulmonary rehabilitation. Am J Respir Crit Care Med 188: e13-e64.

12. Domingo-Salvany A, Lamarca R, Ferrer M, Garcia-Aymerich J, Alonso J, et al. (2002) Health-related quality of life and mortality in male patients with chronic obstructive pulmonary disease. Am J Respir Crit Care Med 166: 680-685.
13. Jones PW, Harding G, Berry P, Wiklund I, Chen WH, et al. (2009) Development and first validation of the COPD assessment test. Eur Respir J 34: 648-654.

14. Carr AJ, Higginson IJ (2001) Are quality of life measures patient centred? BMJ 322: 1357-1360.

15. Murtagh F, Legendre P (2014) Ward's hierarchical agglomerative clustering method: Which algorithms implement ward's criterion?. J Classif 31: 274-295.

16. Wan GJ, Counte MA, Cella DF (1997) The influence of personal expectations on cancer patients' reports of Health-Related quality of life. Psycho-oncology 6: 1-11.

17. Cheng JD, Hitt J, Koczwara B, Schulman KA, Burnett CB, et al. (2000) Impact of quality of life on patient expectations regarding phase I clinical trials. J Clin Oncol 18: 421-428.

18. Welham J, Haire M, Mercer D, Stedman T (2001) A gap approach to exploring quality of life in mental health. Qual Life Res 10: 421-429.

19. Webb BD, Barrera M, Beyene J, Carcao M, Daneman D, et al. (2013) Determinants of quality of life in children with chronic somatic disease: Pilot data from the GapS questionnaire. Qual Life Res 22: 339-349.

20. Jones PW, Harding G, Wiklund I, Berry P, Tabberer M, et al. (2012) Tests of the responsiveness of the COPD assessment test following acute exacerbation and pulmonary rehabilitation. Chest 142: 134-140.

21. Dodd JW, Hogg L, Nolan J, Jefford H, Grant A, et al. (2011) The COPD assessment test (CAT): Response to pulmonary rehabilitation. A multicenter, prospective study. Thorax 66: 425-429.

22. Nishimura K, Izumi T, Tsukino M, Oga T (2002) Dyspnea is a better predictor of 5-year survival than airway obstruction in patients with COPD. Chest 121: 1434-1440.

23. Fan VS, Reiber GE, Diehr P, Burman M, McDonell MB, et al. (2005) Functional status and patient satisfaction. J Gen Intern Med 20: 452-459.

24. Slatore CG, Cecere LM, Reinke LF, Ganzini L, Udris EM, et al. (2010) Patient-clinician communication: associations with important health outcomes among veterans with COPD. Chest 138: 628-634.

25. Orbon $\mathrm{KH}$, Schermer TR, van der Gulden JW, Chavannes $\mathrm{NH}$ Akkermans RP, et al. (2005) Employment status and quality of life in patients with chronic obstructive pulmonary disease. Int Arch Occup Environ Health 78: 467-474.

26. Arne M, Lundin F, Boman G, Janson C, Janson S, et al. (2011) Factors associated with good self-rated health and quality of life in subjects with self-reported COPD. Int J Chron Obstruct Pulmon Dis 6: 511-519.

27. Paulose-Ram R, Su J, McDonald M, Zou KH, Wagner JS, et al. (2012) The burden of chronic obstructive pulmonary disease among employed adults. Int J Chron Obstruct Pulmon Dis 7: 211-219.

28. Andenaes R, Bentsen SB, Hvinden K, Fagermoen MS, Lerdal A (2014) The relationships of self-efficacy, physical activity, and paid work to health-related quality of life among patients with chronic obstructive pulmonary disease (COPD). J Multidiscip Healthc 7: 239-247. 